\title{
Understanding of Kinetic Molecular Theory of Gases in Three Modes of Representation among Tenth-Grade Students in Chemistry
}

\author{
Joje Mar P. Sanchez \\ Cebu Normal University, Cebu City, Philippines \\ https://orcid.org/0000-0002-2224-0190
}

\begin{abstract}
An analysis of students' performance in Kinetic Molecular Theory (KMT) of gases was done to determine the extent of the understanding of these chemistry concepts in three modes of representation, namely macroscopic, microscopic, and symbolic. The study employed one-shot quasi-experimental research where students in Grade 10 at a secondary school in Cebu City were exposed to the Integrated Macro-Micro-Symbolic Approach (IMMSA). A validated posttest tool with macro, micro, and symbolic questions was used in the study. The post-test results revealed that there was a gradual improvement of the students' understanding from a good understanding of macroscopic and microscopic levels to a very good understanding of the symbolic level. Thus, it was concluded that the use of three modes of chemical representation led to a high extent in the understanding of concepts in chemistry. It is recommended that teachers begin their instruction at the macroscopic level and introduce symbols only after the microscopic level.
\end{abstract}

Keywords: Chemistry education, Kinetic Molecular Theory, macroscopic, microscopic, symbolic modes

\section{Introduction}

Understanding chemical concepts and processes is one of the factors that can affect learners' acquisition of scientific, technological, and environmental literacy (Department of Education, 2016; Royal Society of Chemistry, 2011), as well as their preparation for higher education (Royal Society of Chemistry, 2011). Understanding these concepts and processes involves the acquisition of chemical knowledge such as properties of matter and behavior of sub-atomic particles, as well as its application in daily life, industry, and the environment. However, learners have difficulty in acquiring and applying chemical knowledge, which is attributed to the lack of direct observation (Yakmaci-Gucel and Adadan, 2013; Nelson, 2002), the misconceived visualization of the atom (Towns et al., 2012; Wu and Shah, 2004; Harrison and Treagust, 2003), and the inability to derive meaning 
from chemical symbols and equations (Taskin and Bernholt, 2014; Marais and Jordaan, 2000). Due to this difficulty, educators of chemistry incorporate several modes of representation based on the framework developed by Johnstone (1982), called the Chemistry Triangle (Santos and Arroio, 2016; Towns et al., 2012; Talanquer, 2011; Gilbert and Treagust, 2009).

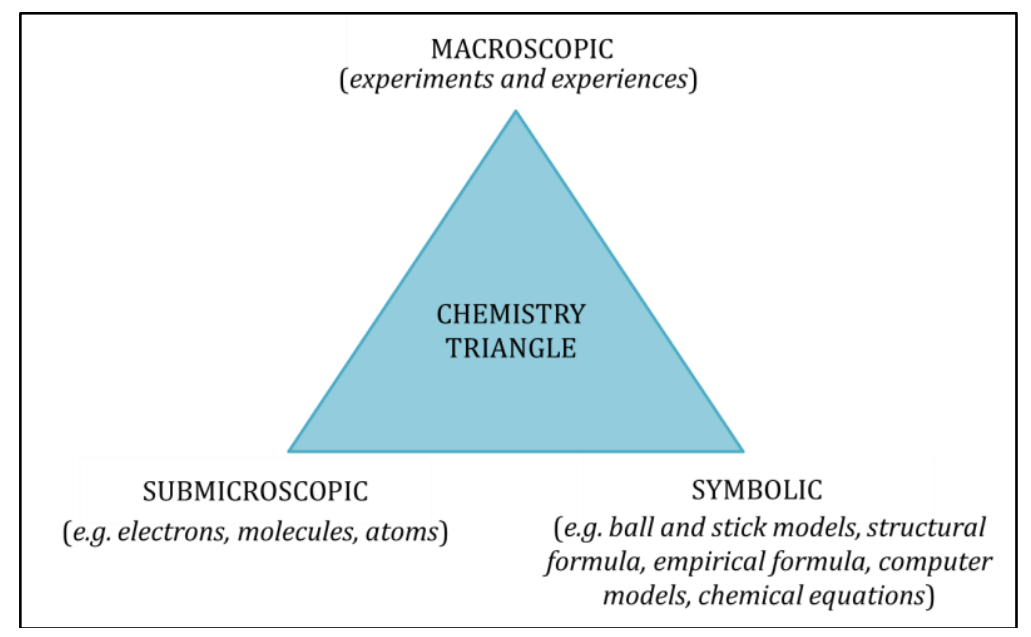

Figure 1. Chemistry Triangle (Johnstone, 1982 in Sanchez, 2017)

The Chemistry Triangle provides an overview of how chemical phenomena could be represented in three closely related modes of representation, which correspond to the three vertices of the framework, namely macroscopic, submicroscopic and symbolic modes (Fahmy, 2016; Talanquer, 2011; Gilbert and Treagust, 2009; Johnstone, 1982). The use of these multiple modes of representation supports the learning of different aspects of chemical phenomena and aid in a deeper understanding of such phenomena (Santos and Arroio, 2016; Ainsworth, 2007).

Several studies have been conducted on the use of the three chemical modes of representation in chemistry. Experimental studies such as those conducted by Sanchez (2017), Wood (2013), and Jaber and Boujaoude (2012) confirmed the effective nature of the integrated use of the modes in enhancing learners' conceptual understanding. Moreover, investigations such as those done by Sanchez (2018), Brandiet (2014), Li and Arshade (2014), and Wood (2013) showed that the learners' ability to link from one mode to another creates a better relational understanding of chemistry. However, there are only a few studies (e.g. Sanchez, 2017; Franco, 2005), which examined the extent of students' understanding of each mode of representation, as well as a handful, which dealt with the Kinetic Molecular Theory (KMT) of gases.

KMT of gases is a general theory that was developed largely by Clausius, Maxwell, and Boltzmann. The theory describes the behavior of gas particles at the molecular level and explains the observable properties of gases as shown in Table 1. 
Table 1. The Kinetic Molecular Theory of Gases (Adapted from España \& Apostol, 2004)

\begin{tabular}{|l|l|}
\hline Properties & Concepts \\
\hline Diffusibility & $\begin{array}{l}\text { Gas particles are in constant motion; thus, they } \\
\text { possess kinetic energy. }\end{array}$ \\
\hline Pressure & $\begin{array}{l}\text { Gas particles collide with one another and hit the } \\
\text { walls of a container. Each of the gas particles applies } \\
\text { force as the particles hit one another. }\end{array}$ \\
\hline $\begin{array}{l}\text { Indefinite Shape and } \\
\text { Volume }\end{array}$ & There is less attractive force between gas particles. \\
\hline $\begin{array}{l}\text { Expansibility } \\
\text { Compressibility and }\end{array}$ & $\begin{array}{l}\text { Gas particles are very small and are far apart from one } \\
\text { another. The spaces between them are too big } \\
\text { compared to the size of each particle. }\end{array}$ \\
\hline $\begin{array}{l}\text { Volume increases with } \\
\text { Temperature }\end{array}$ & $\begin{array}{l}\text { The motion of the gas particles increases as } \\
\text { temperature increases. The average kinetic energy of } \\
\text { gas particles is directly proportional to the absolute } \\
\text { temperature. }\end{array}$ \\
\hline
\end{tabular}

Teaching KMT is crucial as it accounts for and explains several important everyday phenomena (Rhodes, 1992). Several studies incorporating the teaching of KMT include misconceptions about KMT (Erceg et al., 2016; Jauhariyah et al., 2018), and implementation of strategies such as experiment-oriented approach (Wiseman, 1979) and use of computer software (Govender et al. 2016). However, there is a gap in the literature; there have been little or no studies that investigate the understanding of KMT in different modes of representations which led us to investigate the extent of learners' understanding of KMT in three chemical modes of representation.

The results of the study could provide insights into how these modes of representation enhance the understanding of learners in KMT and chemistry in general. Taking into account the learners' extent could offer a better examination of the Chemistry Triangle's utilization in the 21st-century teaching-learning arena.

\subsection{Review of Related Literature}

Multiple representations in chemistry are incorporated into a framework developed by Johnson (1982) called the Chemistry Triangle (Santos and Arroio, 2016; Townset al., 2012; Talanquer, 2011; Gilbert and Treagust, 2009). In the Chemistry Triangle, the chemical representations are represented as vertices of the Triangle: the macroscopic, microscopic, and symbolic modes of representation (Fahmy, 2016; Talanquer, 2011; Gilbert and Treagust, 2009; Johnstone, 1982).

The macroscopic mode of representation provides the learners the description of matter and its processes based on their properties and can be implemented through practical work where they undergo the process of scientific inquiry and enhance science learning (Gilbert, 2008; Millar, 2004). The submicroscopic mode explains how observable phenomena occur at the microscopic level and can be taught through structural and virtual representations, photographs, diagrams, and graphs, which allows the learners to visualize the interaction of particles and create mental models (Santos and Arroio, 2016; Sunyuno et al., 2015; Tasker and Dalton, 2006; Gilbert, 2008). The symbolic mode represents the phenomena using 
chemical symbols, formula expressions, and expressions and can be employed through writing chemical equations and solving problems (Schoenfeld, 2013; Gilbert, 2008). The use of these multiple chemical representations supports students' learning, constrains further interpretation, and leads to a deeper understanding of chemical concepts (Santos and Arroio, 2016; Ainsworth, 2007).

Educational researchers have studied the macroscopic, microscopic, and symbolic modes in teaching and learning chemistry. Sanchez (2017) integrated the three modes into one approach and found that this approach is more effective than the conventional lecture method. Wood (2013) analyzed the instructional use of the three modes and their influence on the conceptual understanding of chemistry. The study noted the influence of macroscopic mode on the understanding of the particulate level and concluded that microscopic models of matter are essential to students' understanding. Jaber and Boujaoude (2012) investigated the shifting between the three modes when learning chemical concepts and revealed that relational understanding can be fostered by explicitly emphasizing the multirepresentational nature of chemical knowledge. Their studies confirmed the effective nature of the integrated use of the modes in enhancing students' conceptual understanding of chemistry.

Studies have also been conducted on students' ability to use the modes and shifting from one mode to another. Sanchez (2018) explored the translational skills of students and found out that an integration of the three modes led to two-way translations when explaining the chemical phenomenon at hand. Brandiet (2014) focused on the use of the three modes in explaining different perspectives of chemical reactions and generalized that students link macroscopic to a symbolic mode more frequently than other linkages such as macro-particulate and symbolic-particulate links. Li and Arshade (2014) revealed that different levels of understanding exist in different modes and that participants emphasized the macroscopic mode, then symbolic and submicroscopic. Wood (2013) states that the knowledge acquired in the macroscopic mode contributed to a better understanding at the microscopic level. In general, these studies showed that the ability to link one mode to another creates a better relational understanding in chemistry.

However, only a few investigations focused on the use of the chemical modes of representation and the understanding of KMT. Sanchez (2017) used the integration of the three modes and found out that this integrated approach has improved students' understanding of KMT. Franco (2005) put his emphasis on the use of the modes in explaining the different concepts of KMT. Students consistently used the same set of premises from KMT but failed to understand certain processes, such as diffusing and dissolving, indicating inconsistencies in explaining both the macroscopic and microscopic modes. Therefore, there is variation in the extent of understanding chemistry in each mode of representation.

The objective of this study is to fill the gap in the literature by investigating the effect of different modes of representation on students' understanding of KMT in different modes of representation. 


\subsection{Statement of the Problem}

This paper aimed to determine the extent of understanding of KMT using the three modes of representations, namely (a) macroscopic, (b) microscopic, and (c) symbolic modes.

\section{Methods}

\subsection{Research Design, Environment, and Participants}

The study utilized a one-shot quasi-experimental design to determine the extent of learners' understanding of KMT. One-shot quasi-experimental research design is a type of experimental design wherein there is only one group (the experimental group). This group is exposed to a teaching-learning intervention called Integrated Macro-Micro-Symbolic Approach (IMMSA), thereby only measuring the post-test performance. The group exposed to IMMSA consisted of 30 randomly selected tenth-grade students ( $N=45$ students) from a secondary education institution in Cebu City, Philippines as participants in this study. These participants were randomly chosen through the fish-bowl method and already had a chemistry course in their previous grade. All participants of the study were coded with an E, such as E1, E13, etc.

\subsection{Research Procedure}

Permission from the school head of the secondary school and informed consent from the participants were sought first before the one-shot experimentation was conducted. In this experimentation, the IMMSA was employed in teaching KMT for a month. IMMSA (Figure 2) is an approach that integrates macroscopic, microscopic, and symbolic modes of representation in teaching a chemical concept or process (Sanchez, 2017).

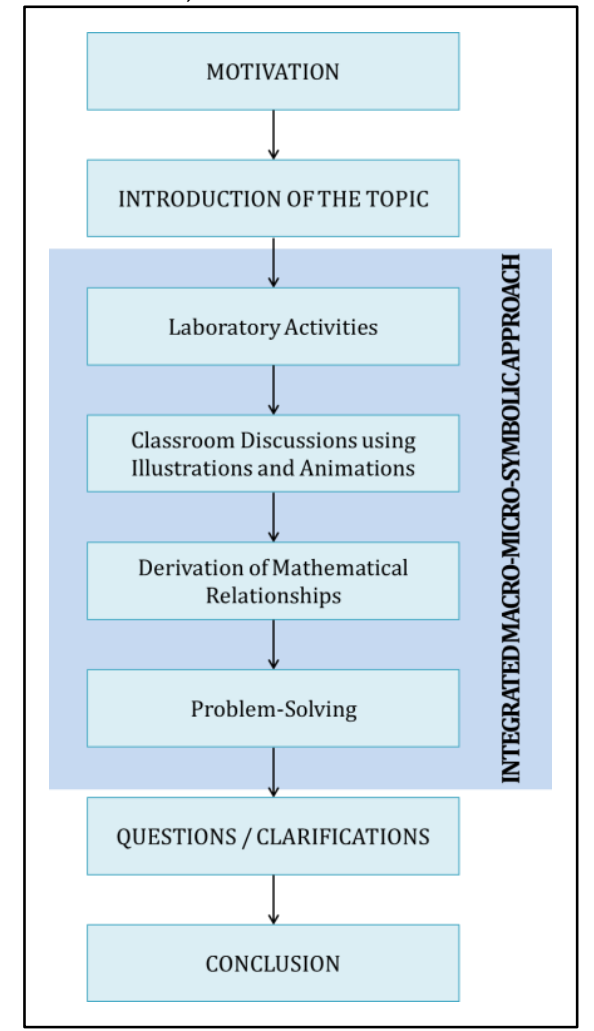

Figure 2. Flow of IMMSA (Sanchez, 2017) 
In IMMSA, the lesson starts with an engaging activity for motivation, and then, the KMT topic is presented. After this phase, laboratory tasks are implemented. These tasks include experiments related to the properties of gases namely diffusion, pressure, volume, compressibility/expansibility, and temperature. Classroom activities follow the lab tasks which include both discussions with illustrations and animations, and construction of diagrams that show the behavior of gases at the level of particles, atoms, and molecules. Relationships between gas properties are inferred, and mathematical relationships are derived according to the lab experiments and the construction activities that the students had. From this derivation, problem-solving tasks are implemented. Afterward, clarifications are entertained, and a generalization about the KMT topic is done. (Refer to Appendix A for a sample flow of the IMMSA.)

After the experimentation period, the participants took the post-test. Analysis of the post-test followed after checking the assessment tool.

\subsection{Research Tool and Analysis}

The research tool used in the study was a post-test. Before administered during post-experimentation, four experts in science and chemistry education validated the research tool. The experts checked the test items to see if they correspond to the competencies in the table of specifications as well as the answer key to see if they are correct, evaluated whether the items measure learning, and assessed if the face value and testing time of the tool is appropriate for the students' age and answering pace. They rated the tool with high construct and content validity with some minor comments. These comments were applied, and the tool was ready for pilot testing. In the pilot testing, the tool was administered to a comparable group of tenth-grade students, subjected to a reliability test, and obtained a reliability coefficient equals to 0.843 , indicating a good, above acceptable reliability.

The tool consists of 30 items, which are divided into five parts. These parts correspond to the five postulates of KMT of gases, namely diffusibility, pressure, volume, compressibility/expansibility, and temperature. Each of these postulates was assessed through a situational analysis where students explain the situation in terms of macroscopic words, construct an illustration showing the behavior of particles at the microscopic level, and infer the relationship between variables and solve for the unknown variable. In this way, the tool consists of multiple-choice, open-ended, and drawing questions that capture the multiple representations of the concepts learned in chemistry. (A sample portion of the research questionnaire is shown in Appendix 2.)

To measure the extent of understanding of the students in each of the five parts of the tool, the researcher gave one point for each correct answer in the multiplechoice items, and gave two points $(\min =0, \max =2)$ for the open-ended questions: 0 point for no or incorrect response, 1 point for an answer that is correct but lacks the aspect that can explain their answer, and 2 points for a correct answer that provides a well-rounded answer. To analyze the responses of the participants, the study used the validated scoring rubric based on the mean of the students' scores: $0.00-0.75$ (Poor, P); 0.76-1.50 (Fair, F); $1.51-2.25$ (Good, G); 2.26-3.00 (Very 
Good). This rubric was utilized as the post-test tool consisted of five parts, each with three subparts; the macroscopic and microscopic modes had 3 points while the symbolic mode had 2 points.

\section{Results and Discussions}

The students' understanding of different modes of representation was obtained from the post-test performance of the students exposed to IMMSA. The statistical analysis of the stated performance is shown in Table 2, which is divided according to topics and three modes of representation.

Table 2. Extent of students' understanding in KMT of gases

\begin{tabular}{|c|c|c|c|c|c|c|}
\hline \multirow{2}{*}{ Topic $\quad$ Mode } & \multicolumn{2}{|c|}{ Macroscopic ${ }^{\dagger}$} & \multicolumn{2}{|c|}{ Microscopic ${ }^{\dagger}$} & \multicolumn{2}{|c|}{ Symbolic ${ }^{\dagger}$} \\
\hline & Mean* & SD & Mean* & SD & Mean* & SD \\
\hline Diffusibility & $\begin{array}{c}1.13 \\
(\mathrm{~F})\end{array}$ & 1.30 & $\begin{array}{l}1.47 \\
(\mathrm{~F})\end{array}$ & 1.06 & $\begin{array}{l}1.07 \\
(\mathrm{G})\end{array}$ & 0.59 \\
\hline Pressure & $\begin{array}{l}1.53 \\
(G)\end{array}$ & 1.25 & $\begin{array}{l}1.60 \\
(G)\end{array}$ & 0.91 & $\begin{array}{l}1.87 \\
(\mathrm{VG})\end{array}$ & 0.52 \\
\hline Volume & $\begin{array}{l}2.80 \\
(\mathrm{VG})\end{array}$ & 0.56 & $\begin{array}{l}1.60 \\
(G)\end{array}$ & 1.06 & $\begin{array}{l}1.27 \\
(\mathrm{G})\end{array}$ & 0.80 \\
\hline $\begin{array}{l}\text { Compressibility/ } \\
\text { Expansibility }\end{array}$ & $\begin{array}{l}2.00 \\
(\mathrm{G})\end{array}$ & 1.31 & $\begin{array}{c}1.27 \\
(\mathrm{~F})\end{array}$ & 1.22 & $\begin{array}{l}1.33 \\
(\mathrm{G})\end{array}$ & 0.82 \\
\hline Temperature & $\begin{array}{l}2.53 \\
(\mathrm{VG})\end{array}$ & 0.52 & $\begin{array}{l}1.80 \\
(\mathrm{G})\end{array}$ & 0.77 & $\begin{array}{l}1.80 \\
\text { (VG) }\end{array}$ & 0.56 \\
\hline Overall & $\begin{array}{l}2.00 \\
(G)\end{array}$ & 0.99 & $\begin{array}{l}1.55 \\
(G)\end{array}$ & 1.00 & $\begin{array}{l}1.47 \\
\text { (VG) }\end{array}$ & 0.66 \\
\hline
\end{tabular}

The results (Table 2) shows that the extent of the students' understanding of diffusibility and pressure is highest at the symbolic level, while on volume, the highest is at the macroscopic level. Both compressibility/expansibility and the temperature have their highest extent at the microscopic level. This suggests that certain topics in chemistry could be best understood using one mode of representation, e.g., diffusibility is best taught using the symbolic mode. However, the use of other modes enriches the learning of chemistry and offers a more effective medium of understanding concepts and principles from different perspectives (Jaber and Boujaoude, 2012; Ainsworth, 2007).

\subsection{Macroscopic Mode}

The Very Good understanding of the topics on volume and temperature and the Good understanding of pressure and compressibility/expansibility could be because the given situations were everyday scenarios, which were applications of the postulates of KMT discussed during the study. It was noted that the terms used by students in explaining various phenomena were scientific terms first introduced during the laboratory sessions of the study. Some of these terms are shown in the answers of E13 in Figure 3. 


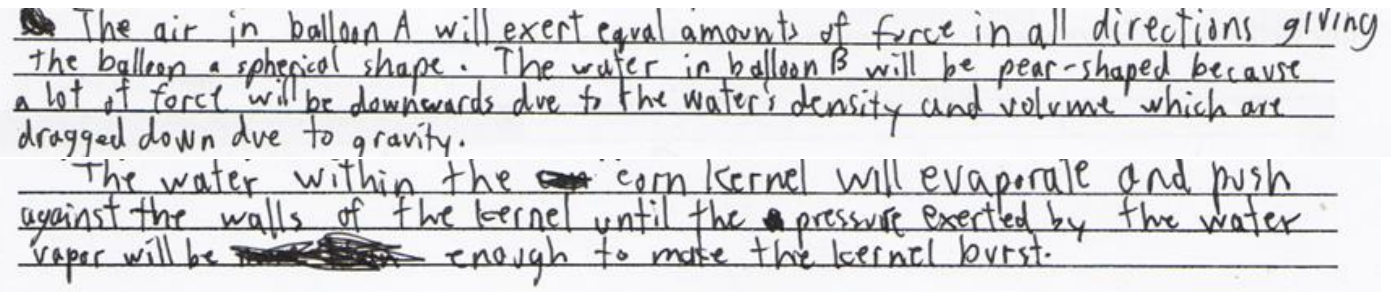

Figure 3. Sample answers from Student E13 on macroscopic questions:

(1) volume, and (2) temperature

Based on Figure 3, the terms used by the student to explain the given phenomena on volume and temperature include force, density, volume, gravity, evaporate, pressure, water vapor, and burst. The association of these terms from the laboratory experiences conformed to the study of Brandiet (2014), which noted that students predicted chemical phenomena by attempting to use their experiences in the laboratory. It was implied that students remember more when they are engaged in hands-on-minds-on activities in the science laboratory.

However, in the case of the topic on diffusibility, students only got a Fair understanding using the macroscopic mode. The situation about diffusibility states: "Leonard wears his perfume inside his air-conditioned classroom". The low understanding of this item might be due to differing vicarious observations that the students had since they tend not to be exposed to the phenomena in real life. During the conduct of the study, one anecdote might explain why students had a Fair conceptual understanding of the diffusibility of perfume. At some point in the course of the laboratory work, the experiment required that they use perfume. Surprisingly, they were not able to do it because they contended that, in their own words, "Who will be bringing perfume in an all-boys school?" This means that they had minimal or no experience at all of the phenomenon firsthand or they had it secondhand. Learning through direct experience should involve living through things to obtain long-term knowledge (Rizk, 2011). Though, the students still explained the phenomenon using the premises of KMT as evident in the Figure 3. Since they are not exposed to or are vicariously exposed to it, they tend to have different conceptions and use different premises of a theory to explain it (Franco, 2005).

Despite having a Fair rating in diffusibility, the students obtained a Good understanding of the macroscopic mode. This Good understanding could be the result of the instruction of chemistry at the IMMSA, which is strongly founded by what is observed by the senses during the laboratory experiments. This strong foundation on macroscopic mode was asserted by Jaber and Boujaoude (2012), who stated that students tend to interpret chemical phenomena more at the macroscopic level. Concepts of chemistry should be rooted in real everyday life to have a sound experience before advancing to more abstract and complex concepts.

The inclusion of laboratory activities in the IMMSA in teaching Chemistry might solve students' lack of exposure to the macroscopic mode. It is through exposure that students gain interest and enjoyment, enhance the learning of scientific 
concepts and skills, gain insights in the scientific method, and develop expertise, and a scientific attitudes (Gilbert, 2008; Millar, 2004). Thus, performance in chemistry could be enhanced and a greater appreciation for the subject matter be developed.

\subsection{Microscopic Mode}

The students' Good level of understanding of pressure, volume, and temperature using the microscopic mode might be because they already had exposure to the macroscopic level and had ideas about the behavior of matter at the level of atoms and molecules. This led to a better understanding of the topics as they construct their visualization out from the given phenomena. Figure 4 shows sample illustrations on the situations for pressure, volume, and temperature constructed by Student E11.

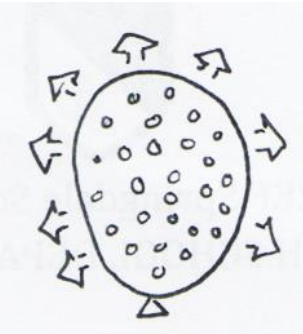

(a)

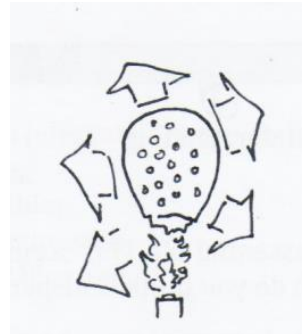

(b)

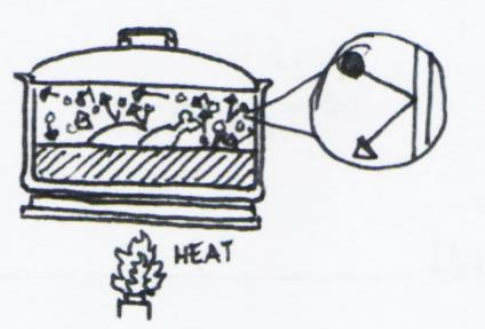

(c)

Figure 4. Sample illustrations of Student E11 on microscopic questions:

(a) volume, (b) temperature and (c) pressure.

It is noted in Figure 4 that the illustrations complement the students' answers in macroscopic mode. For instance, Student E11 stated using the macroscopic mode, "Because the heat will cause the water molecules inside the kernels to expand, causing the kernels to have more pressure inside of it than the outside of it. Eventually making the kernels rupture and burst." This statement was embodied in his construction of the illustration and provided more meaning as it included the behavior of molecules at the submicroscopic level. This makes the microscopic mode more complex and semi-abstract because students were introduced to some conventions, which included the representation of molecules as round particles, and the direction of the molecular motion as arrows, and the inclusion of the conditions about specific phenomena. This function of the microscopic level cohered with Ainsworth's (2007) assertion that various ways of representing phenomena support learning by complementing one another with multiple perspectives.

In the case of diffusibility and compressibility/expansibility, students obtained only a Fair understanding. This might be partly due to the inconclusive experience in the macroscopic level that illustrating such experience leads to incorrect, misconceived iconic representation. This conformed to the study of Jaber and Bougaoude (2012), which asserted that the main hindrance to conceptual understanding could be attributed to students' inappropriate application of macroscopic reasoning to explain phenomena at the microscopic level. Additionally, it might also be that the conventions are too simple that they forgot to use them or are too complex that they have difficulty in using them. A sample 
illustration by Student E7 represented in Figure 5 shows some problems with the use of conventions.

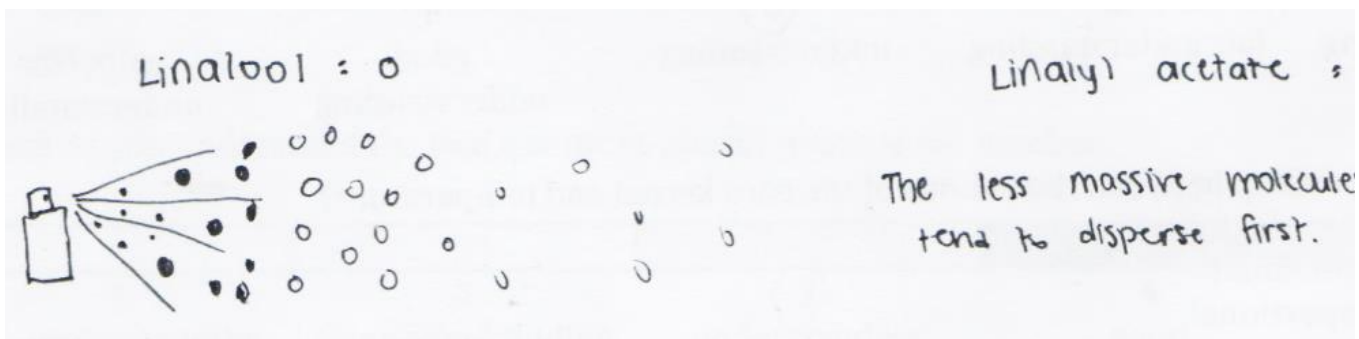

Figure 5. Sample illustration on diffusibility as constructed by Student E7.

Based on Figure 5, the students had illustrated the behavior of linalool and linalyl acetate during the diffusion process by using a dichotomous color key to differentiate between the two types of gas molecules: the former molecule is white, and the latter is black. In addition to this, the illustration does not depict any arrows showing the motion of molecules, but the lines originating from the perfume bottle may suggest the direction of motion. Lastly, it was noted that the illustration did not account for the size of the molecules, as there were small and big linalool and linalyl acetate molecules. This incomplete depiction of the behavior of molecules might be because the submicroscopic level of understanding cannot be seen directly and is accessible only by imagination. This what makes microscopic mode difficult for both students and teachers (Touli et al., 2012; Nelson, 2002).

The relatively lower mean of the microscopic mode than the macroscopic mode negated the results of Wood (2013). In her study, only one instructor had produced significant mean gain from the pretest to the post-test, and this instructor was the only one who significantly used microscopic mode in both lecture and laboratory formats. This observation implied that the incorporation of descriptions of "how" and "why" of particle interactions helped the students to have a better connection among the three modes of representation. Such incorporation led to a better understanding at the symbolic level. Thus, chemical understanding has shown to be improved. With this, misconceptions at the submicroscopic level might be avoided.

Nevertheless, the students gained an overall qualitative rating of Good understanding using the microscopic mode, which was the same for the macroscopic mode. This might be because they were engaged first in laboratory activities. From such activities, they became more active learners as they took part in the construction of an illustration showing the behavior of gases and developed more complex skills. This agreed with the implication of McDermott (2009) that embedding illustrations in communicating scientific information result in a better level of performance. Davidowitz and Chittleborough (2009) added that the construction of illustrations and diagrams is consistent with constructivism that requires students to demonstrate their understanding and receive feedback; thus, these iconic representations become an active tool for learning. The students exposed to this mode translated macroscopic activities into a process in which 
they take part in the construction and development of comprehension, which can lead to a higher understanding in the subsequent symbolic mode (Kincheloe and Horn, 2007).

\subsection{Symbolic Mode}

The students had a Very Good understanding of pressure and temperature, and a Good understanding of diffusibility, volume, and compressibility/ expansibility. This indicated that they had a very good chemical understanding at the abstract level. This could signify that the high-rated performance at this level was due to the gradual process brought about by the IMMSA. Since they are exposed already to the laboratory experiments and illustration construction activities, they gained mastery of the phenomena and extended the concrete and iconic nature of the representation to the most abstract one.

Shown in Figure 6 is a sample snippet of the symbolic mode as answered by Student E8.

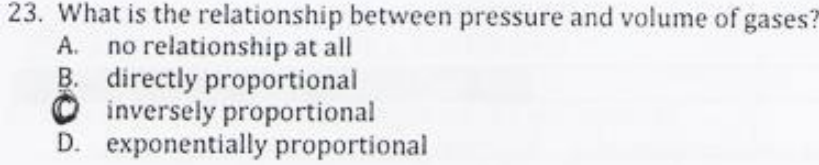

24. If at a pressure of $1 \mathrm{~atm}$, the volume of gases in the lungs is around $22.4 \mathrm{~L}$. Jeferson decided not to go up directly, but to swim further at 66 feet where the pressure is $2 \mathrm{~atm}$. What is the volume of the gases in his lungs at this depth?
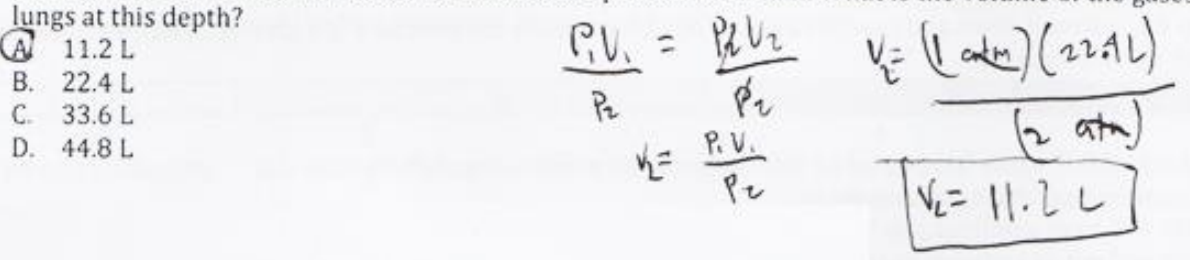

Figure 6. Sample snippet from Student E8's test on symbolic questions.

Figure 6 represents one of the students who answered symbolic questions correctly. It is noted that the student answered correctly the inverse relationship between pressure and volume, and the problem stated after. The relationship between two variables was determined by the students when they were exposed to the laboratory and illustration activities, wherein they inductively infer the direct, inverse, and no relationship among variables. Subsequently, they derived the formula based on the relationship obtained, gave meaning to the symbols used, and solved the problem. Other than that, it is also noted that the student showed a complete solution, as he did write the formula, derive the formula of the asked quantity, substitute corresponding quantities, use correct unit cancellation, solve for the answer, and box the final answer. This shows that students who were exposed to the IMMSA created a meaningful association through symbols and used a systematic convention to overcome some deficiencies, which occur at the symbolic level. This is in line with Marais and Jordaan's (2000) conclusion that stated that students should be immersed in symbol-meaning making and be purposefully taught with symbolisms. 
The overall Very Good understanding of the students in the symbolic level reflected the effective role of the IMMSA in teaching chemistry as the students attained superior use of learning the highest level of the three-tiered model of learning (Sanchez, 2017). The superior use of learning is reflected when they allow concepts to be compacted in their minds, in such a way that they assign symbols that can represent their learning. Assigning symbols, such as $P$ for pressure and $K$ as a unit for temperature, means mastery of learning (Kincheloe and Horn, 2007).

\subsection{Interplay of the Three Modes of Chemical Representation}

The interplay of the macroscopic, microscopic, and symbolic modes of representation indicate the extent of how the students move from one mode to another. This interplay can be exemplified in Figure 7.

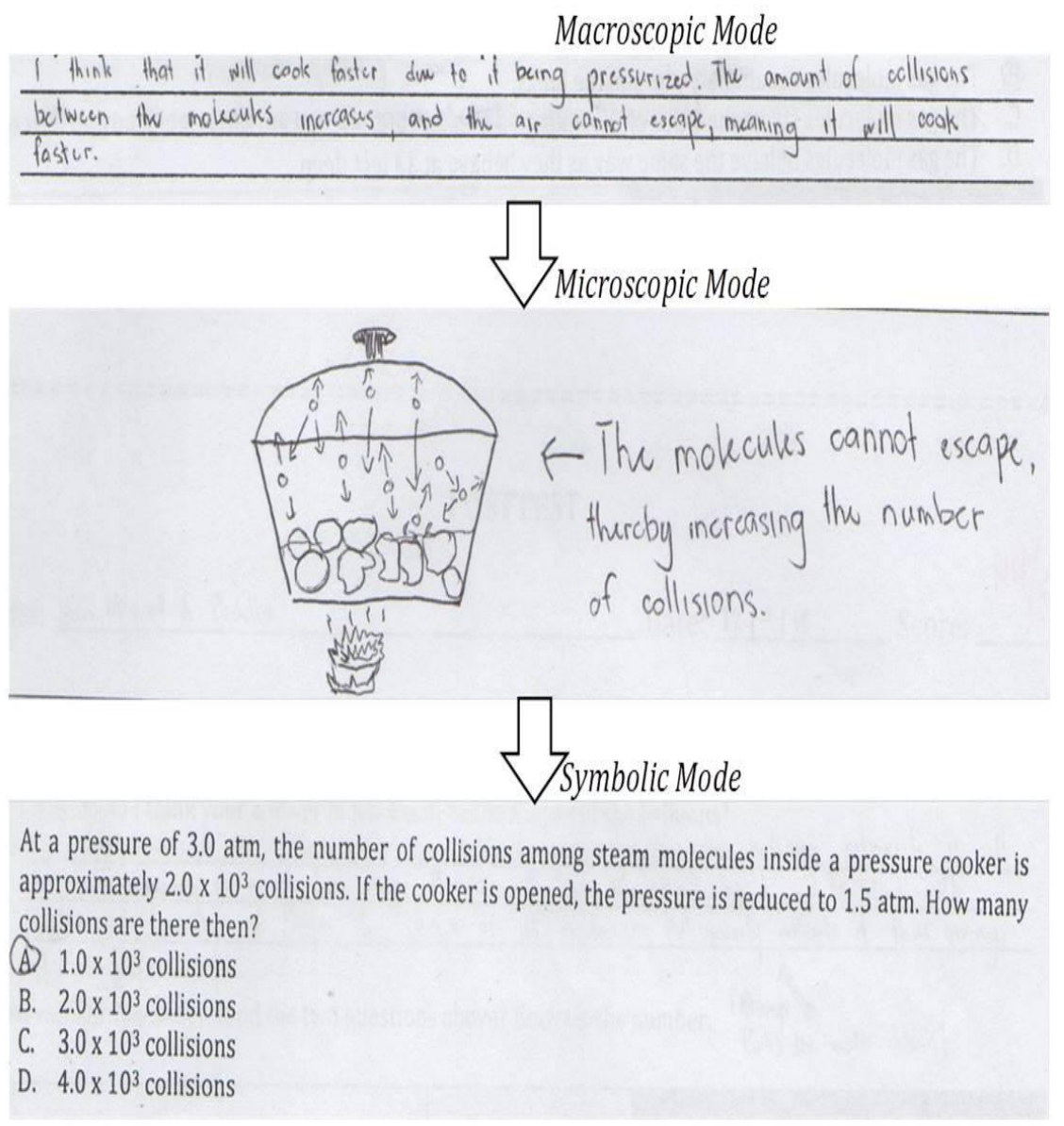

Figure 7. An Interplay among Macro, Micro and Symbolic Modes to describe how a Pressure Cooker works

Figure 7 shows the interplay of three modes of representation as Student E9 answered how a pressure cooker works. Firstly, he described that the pressure cooker works because of the concept of pressure and collision. Then, he constructed an illustration, which shows how pressure affects the cooking of humba in the cooker. Lastly, he answered a problem-based question in which he utilized the relationship between pressure and the number of collisions in the 
microscopic mode in order to answer it. This indicated that the interplay is complete, but only one-way interplay originating from the macroscopic terminal, thereby recommending further studies which would take into consideration the other originating terminals, namely the macroscopic and symbolic terminals.

\section{Conclusion, Recommendations, and Limitations}

The use of the three different chemical modes of representation at the appropriate time and levels led to a high extent of understanding of concepts in chemistry, specifically in the KMT of gases. Engagement in hands-on-minds-on activities in laboratory activities provides a springboard for understanding concepts and principles. When these activities are translated into a process of illustration construction, students take part in the development of comprehension of the behavior of matter at the submicroscopic level. This eventually leads to the derivation of mental relationships, and assignment of symbols such as $P$ and $\mathrm{K}$, reflecting more active learning in chemistry at the symbolic level. Therefore, the use of different modes enriches the learning of chemistry and offers a more effective medium of understanding concepts and principles from different perspectives.

This study recommends that teachers begin instruction at the macroscopic level, where they implement laboratory exercise, include the microscopic mode in pedagogy, and introduce symbols, formulas, and problem-based activities after students understand the phenomena in the atomic, subatomic, and molecular level.

The study is limited to exploring the use of the macroscopic, microscopic, and symbolic modes of representation to the understanding of KMT among tenthgrade students. With this, the results of the study may provide baseline data to further studies that will deal with the use of the modes in other grade levels in chemistry or in other fields of science education. A pre-test-post-test with a control design is recommended for future studies to determine how concepts in chemistry and problem-solving skills can be improved by each mode of representation.

\section{References}

Ainsworth, S. (2007). The educational value of multiple representations when learning complex scientific concepts. In: J. K. Gilbert, M. Reiner \& M. Nakhleh (Eds.). Visualization: Theory and Practice in Science Education (Vol. 3, pp. 191-208). Springer. https://doi.org/10.1007/978-1-4020-5267-5_9

Brandiet, A. (2014). Investigating students' understanding of the symbolic, macroscopic, and particulate domains of oxidation-reduction and the development of the redox concept inventory [Ph.D. Dissertation] Miami University. https://www.etd.ohiolink.edu/pg_10?0:NO:10:P10_ETD_SUBID:96474

Davidowitz, B., \& Chittleborough, G. (2009). Linking the macroscopic and submicroscopic levels: Diagrams. In: J. K. Gilber \& D. Treagust (Eds.). Multiple Representations in Chemical Education (Vol. 4, pp. 169-191). Springer. https://doi.org/10.1007/978-1-4020-8872-8_9

Department of Education. (2016). K to 12 Curriculum Guide - SCIENCE (Grades 3 to 10). Republic of the Phillippines, Department of Education. 
https://www.deped.gov.ph/wp-content/uploads/2019/01/Science-CG_withtagged-sci-equipment_revised.pdf

Erceg, N., Aviani, I., Mešić, V., Glunčić, M., \& Žauhar, G. (2016). Development of the kinetic molecular theory of gases concept inventory: Preliminary results on university students' misconceptions. Physical Review Physics Education Research, 12, Article 020139. https:// doi.org/10.1103/PhysRevPhysEducRes.12.020139

España, R., \& Apostol, J. (2004). Science III- Chemistry (New Edition). Abiva Publishing House, Inc.

Fahmy, A. F. M. (2016). Uses of systemic approach and chemist's triangle in teaching and learning Chemistry: Systemic Chemistry triangle [SCT] as a teaching \& learning strategy. Journal of African Chemical Education, 6(2), 69-95.

Franco, A. (2005). Secondary students' multiple representations relating to the structure of matter. Royal Society of Chemistry: University of Cambridge.

Gilbert, J. K. (2008). Visualization: An emergent field of practice and enquiry in Science education. In: J. K. Gilbert, M. Reiner \& M. Nakhleh, (Eds.). Visualization: Theory and Practice in Science Education (Vol. 3, pp. 3-24). Springer. https://doi.org/10.1007/978-1-4020-5267-5_1

Gilbert, J. K. \& Treagust, D. (Eds.). (2009). Multiple Representations in Chemical Education. Springer.

Govender, N., Good, M. A., \& Sibanda, D. (2016). Preservice teachers collaborative learning of gases and kinetic molecular theory (KMT) using CmapTools®: A variation theory analysis. International Journal of Sciences and Research, 72(12), 394412. http:/doi.org/ 10.21506/j.ponte.2016.12.56

Harrison, A. G., \& Treagust, D. F. (2003). The particulate nature of matter: Challenges in understanding the submicroscopic world. In: J. K. Gilbert, O. de Jong, R. Justin, D. F. Treagust and J. H. van Diel (Eds). Chemical Education Towards Research-based Practice (Vol. 17, pp. 189-212. Springer. https://doi.org/10.1007/0-306-47977-X_9

Jauhariyah, M. N. R., Suprapto, N., Suliyanah, Admoko, S., Setyarsih, W., Harizah, Z., \& Zulfa, I. (2018). The students' misconceptions profile on chapter gas kinetic theory. Journal of Physics: Conference Series, 997, Article 012031. http://doi.org/ 10.1088/1742-6596/997/1/012031

Johnstone, A. (1982). Macro- and micro-chemistry. School Science Review, 64, 377-379.

Kincheloe, J., \& Horn, R. (2007). The Praeger handbook of education and psychology (Vol. 1). Connecticut: Praeger Publishers

Li, W., \& Arshad, M. (2014). Applications of multiple representation levels in redox reactions among tenth grade Chemistry teachers. Journal of Turkish Science Education, 11, 35-52.

Marais, P., \& Jordaan, F. (2000). Are we taking symbolic language for granted?. Journal of Chemical Education, 78(10), 1355-1357. https://doi.org/10.1021/ed077p1355

McDermott, M. (2009). The impact of embedding multiple modes of representation on the student construction of chemistry knowledge. University of Iowa. (Ph.D. Dissertation). University of Iowa. https://www.mobt3ath.com/uplode/book/book-23735.pdf

Millar, R. (2004). The Role of Practical Work in the Teaching and Learning of Science. Department of Educational Studies, The University of York. https://sites.nationalacademies.org/cs/groups/dbassesite/documents/webpa ge/dbasse_073330.pdf

Nelson, P. (2002). Teaching Chemistry progressively: from substances, to atoms and molecules, to electrons and nuclei. Chemical Education Research and Practice Europe, 3(2), 215-228. https://doi.org/10.1039/B2RP90017C 
Rhodes, G. (1992). Does a one-molecule gas obey Boyle's Law? Journal of Chemical Education, 69(1), 16. https://doi.org/10.1021/ed069p16

Rizk, L. (2011, August 13-18). Learning by doing: Toward an experiential approach to professional development. World Library and Information Congress, Puerto Rico.

Royal Society of Chemistry. (2011). Global framework for Chemistry education for 11-14 and 14-16 ages ranges. http://www.rsc.org/images/ DEVELOPING\%20A\%20GLOBAL\%20FRAMEWORK\%20FOR\%20CHEMISTRY \%20EDUCATION_tcm18-207914.pdf

Sanchez, J. M. (2017). Integrated macro-micro-symbolic approach in teaching secondary Chemistry. Kimika, 28(2), 22-29.

Sanchez, J. M. (2018). Translational skills of students in Chemistry. Science Education International, 29(4), 214-219.

Santos, V. C., \& Arroio, A. The representational levels: Influences and contributions to research in chemical education. Journal of Turkish Science Education, 13(1), 3-18.

Schoenfeld, A. (2013). Reflections on problem solving theory and practice. The Mathematics Enthusiast, 10, 1-2.

Sunyuno, Yuanita, L., \& Ibrahim, M. (2015). Supporting students in learning with multiple representation to improve student mental models on atomic structure concepts. Science Education International, 26(2), 104-125.

Talanquer, V. (2011). Macro, submicro, and symbolic: The many faces of the Chemistry triplet. International Journal of Science Education, 33(2), 179-195. https:// doi.org/10.1080/09500690903386435

Tasker, R., \& Dalton, R. (2006). Research into practice: Visualization of the molecular world using animations. Chemical Education Research and Practice, 7, 141-159. https://doi.org/10.1039/B5RP90020D

Taskin, V., \& Bernholt, S. (2014). Students' understanding of chemical formulae: A review of empirical research. International Journal of Science Education, 36(1), 157-185. https://doi.org/10.1080/09500693.2012.744492

Touli, E. H., Talbi, M., \& Radid, M. (2012). Teaching-learning of chemistry: Analysis of representations of learners on the modeling of chemical transformation. ProcediaSocial and Behavioral Sciences, 46, 47-52. https://doi.org/10.1016/j.sbspro.2012.05.065

Towns, M., Raker, J., Becker, N., Harle, M., \& Sutcliffe, J. (2012). The biochemistry tetrahedron and the development of the taxonomy of biochemistry external representations (TOBER). Chemical Education Research and Practice, 13, 296-306. https://doi.org/10.1039/c2rp00014h

Wiseman Jr., FL. (1979). An experiment oriented approach to teaching the kinetic molecular theory. Journal of Chemical Education, 56(4), 233. https://doi.org/10.1021/ed056p233

Wood, L. (2013). Representing Chemistry: How instructional use of symbolic, microscopic and macroscopic modes influences student conceptual understanding in Chemistry. (Ph.D. Dissertation). Arizona State University. https://repository.asu.edu/attachments/114440/content/Wood_asu_0010E_13 174.pdf

Wu, H. K., \& Shah, P. (2004). Exploring visuospatial thinking in chemistry learning. Science Education, 88(3), 465-492. https://doi.org/10.1002/sce.10126

Yakmaci-Guzel, B., \& Adadan, E. (2013). Use of multiple representations in developing preservice chemistry teachers' understanding of the structure of matter. International Journal of Environmental and Science Education, 8(1), 109-130. 


\section{Appendix 1}

\section{Sample IMMSA flow in teaching Pressure and Volume}

Learning Activity 1: Laboratory Experiment ( 2 days $=1$ hour and 40 minutes)

1. Prelab: Students are asked about pressure and volume.

2. Lab Proper: Students are given with three experiments on drinking from a straw, and syringe experiments A and B. While doing the experimental procedures, they are to observe and record their results in a tabular format. Cleaning the working area, and returning of apparatus follows.

3. Postlab: Students are to answer analysis questions, and write conclusion derived from the results of the experiment.

Learning Activity 2: Illustration Activity ( 2 days $=1$ hour and 40 minutes)

1. Pre-construction: Students are asked questions related to the lab experiment done.

2. Construction Proper: Students are divided into four groups. Each group is tasked to construct an illustration out of the results of the experiment done. For example, the students will illustrate the behavior of the molecules during drinking from a straw.

3. Post-construction: One representative from each group explains the illustration in terms of the behavior of molecules during such processes.

Learning Activity 2: Problem Solving ( 2 days $=1$ hour and 40 minutes)

1. Pre-problem solving: Students are asked about the relationship between pressure and volume, and temperature and volume. This primary questioning leads to the derivation of Boyle's Law and Charles's Law.

2. Problem Solving: After inferring the relationships above and derivation of Graham's Law, the students are to answer one or two conceptual problems. Then, problem solving activities are employed to them, where their answers follow the GAFSA format (Given, Asked, Formula, Solution and Answer).

3. Post-problem solving: Checking of papers follows. After this, one or two students are asked to create situations where Boyle's Law or Charles's Law could be applied. This serves as the conclusion and verification stage of the lesson. 


\section{Appendix 2}

\section{Sample Portion of the Validated Research Tool}

Situation: Jaime puts a handful of corn kernels in a beaker with a small amount of oil.

1. What do you will Conner observe after heating the beaker containing corn kernels and oil?
A. The corn kernels will burst
B. The corn kernels will shrink.
C. The corn kernels will change color.
D. Nothing will happen to the corn kernels.

2. Why do you think your answer is no.1 will happen? (constructive response)

3. Which of the following is CORRECT about the water molecules present in the corn kernel during the heating?

A. The water molecules strike the walls of the corn kernel at a greater rate.

B. The water molecules strike the walls of the corn kernel at a lesser rate.

C. The water molecules strike the walls of the corn kernel with an equal rate.

D. The water molecules do not strike the walls of the corn kernel when heated.

4. How do you represent the behavior of the molecules in no. 3? Illustrate it below. (constructing response)

5. What is the relationship between the volume of the corn kernel and temperature?
A. no relationship at all
B. directly proportional
C. inversely proportional
D. exponentially proportional

6. At a temperature of $298.15 \mathrm{~K}$, the corn kernel has a volume of $3.0 \mathrm{~mL}$. After raising the temperature to $323.15 \mathrm{~K}$, what is the volume of the kernel? (problem-solving response) 